\title{
Mass mortality of Madagascar radiated tortoise caused by road construction
}

\author{
Steven M. Goodman, Mark Pidgeon and Sheila O'Connor
}

\begin{abstract}
The Madagascar radiated tortoise, already beset by habitat destruction and human exploitation, suffered another blow when many individuals died as a result of a road improvement scheme in the heart of their range. When the authors of this paper reported the problem the Malagasy government authorities acted swiftly to modify the road to prevent tortoises being trapped there in the future.
\end{abstract}

The Madagascar radiated tortoise Geochelone radiata, which is endemic to the spiny forest zone of southern Madagascar, has received attention from the conservation community in the past few years because of population declines caused by destruction of natural habitat, and exploitation for food and the pet trade (Juvik, 1975; Jenkins, 1987; Durrell et al., 1989). This species is listed on Appendix I (prohibiting all commercial trade) of the Convention on International Trade in Endangered Species of Wild Flora and Fauna (CITES), to which the Democratic Republic of Madagascar is a party.

On 30 December 1992, while driving between Cap Sainte Marie and Beloha in the extreme south of Madagascar, we came across considerable numbers of radiated tortoises along the road. The area is known as the Karimbola Plateau and is in the heart of the radiated tortoise's range (Juvik, 1975) (Figure 1). A section of the main road between Ankororoka $\left(45^{\circ} 11^{\prime} \mathrm{E}, 25^{\circ} 30^{\prime} \mathrm{S}\right)$ and Beloha ( $45^{\circ}$ $03^{\prime} \mathrm{E}, 25^{\circ} 10^{\prime} \mathrm{S}$ ) was in the process of being improved by 'Petites et Moyennes Entreprises' with funding from the World Bank (Project 8, Crédit Pasage/Volet 'Route', Ministère des Travaux Publique, Antananarivo, pers. comm.). The new road was cut out of the old road bed and enlarged. It had steep banks (often close to vertical) bordered by drainage ditches generally $20-50 \mathrm{~cm}$ deep. Generally, every $200 \mathrm{~m}$ canals (approximately $2 \mathrm{~m}$ long) had been cut through the bank to carry water from the drainage ditches to reservoir pits (approximately $30 \mathrm{~cm}$ deep). Not all of the new road had been completed and some sections still had the original gradually sloping banks. In other places construction was in progress, and deviations funnelled traffic away from the main road.

In the week before our trip, heavy rain had fallen in the area and thus our visit coincided with a period when tortoises were particularly active. After entering the main road at Ankororoka from the track that leads to Cap Sainte Marie, we immediately noticed G. radiata along the road and in the next $13 \mathrm{~km}$ we counted 28 tortoises (dead and alive). Thereafter, and until $7.5 \mathrm{~km}$ south of Beloha, we recorded all individuals, their position to the nearest $0.1 \mathrm{~km}$ (using the car's odometer), and whether they were dead or alive. Along this latter portion of road, which was $29.8 \mathrm{~km}$ long (not including $3.2 \mathrm{~km}$ of road deviations and $4.0 \mathrm{~km}$ with low banks allowing an exit route for tortoises from the road), 89 tortoises were counted, of which 27 were alive and rescued and 62 dead. In total there were 117 tortoises along $42.8 \mathrm{~km}$ of road. This is an average of nearly three individuals per kilometre of road. The tortoises were composed of all age classes. Along the $29.8-\mathrm{km}$ section of road the average distance between individuals was $0.22 \mathrm{~km}(n=81$, range $=0.0-1.2 \mathrm{~km}, \mathrm{SD}=$ $0.27)$. The greatest number of tortoises found along $1 \mathrm{~km}$ of road was 12 . No other species of tortoise was observed. Juvik (1975) reported that in southern Madagascar in 1974, after heavy rain, tortoise density along Route Nationale no. 10 was up to one individual per 
kilometre of road. These data were from an area that is at the margin of this species's range, and also in a region where they are exploited. Thus, our recent estimate of radiated tortoise density along the Karimbola Plateau may be closer to natural densities.

Apparently the tortoises entered the road bed by crossing over the few sections with low banks, by negotiating places where banks were not exceptionally steep, or just falling down from the upper portion of the bank. Thereafter many were trapped along the road banks, in ditches, or in drainage canals. The angle of the banks and ditches was too steep for them to maintain a foothold. In several cases we found tortoises on their backs; these individuals probably fell while trying to climb

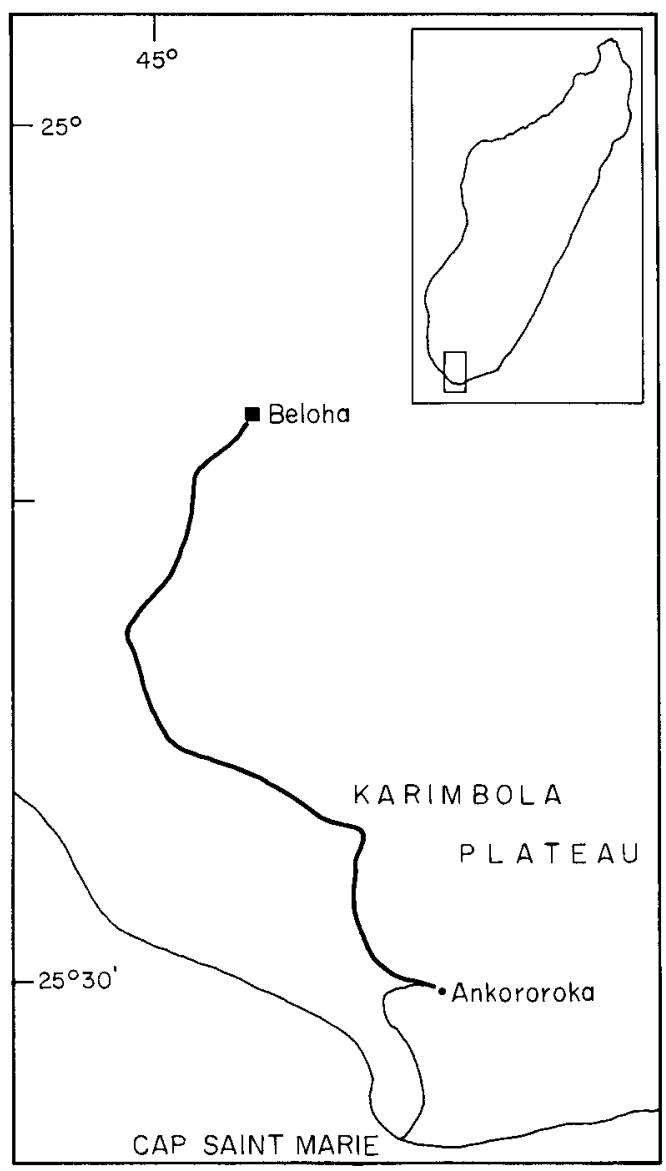

Figure 1. Sketch map of southern Madagascar showing the route of the road where improvements resulted in the deaths of radiated tortoises. out of or into the road bed. Tortoises presumably succumbed to dehydration from exposure to the sun, drowning caused by recent heavy rains, or collisions with motor vehicles or oxen carts. Dead tortoises varied from being relatively fresh (less than a few days old) to old skeletons and carapaces. This situation could be avoided in the future by not cutting the road bed so deep, by having more gradual banks, or erecting ramps every few hundred metres between the road bed and the bank. In addition, the drainage pits should have some kind of entrance guard or contain escape routes such as ramps. These measures would allow the tortoises to move across the road bed without being trapped.

Although we did not record information on the relative position of each tortoise to the roadside habitat, it was clear that they were moving between a range of ecotypes, including relatively intact subarid thorn scrub forest, degraded forest, pasture and cultivated land. Tortoise density was distinctly lower near degraded areas and higher near remaining forest parcels. We did not check all the drainage canals that terminated in large pits, nor do we have an estimate of the numbers of tortoises removed from the road by humans. Thus, our estimate of radiated tortoise density along the road is certainly conservative.

The predominant cultural group inhabiting the region is the Antandroy, for whom the consumption of tortoise is taboo. In several cases we found live tortoises in the road bed at the edge of or moving through Tandroy villages, which would support the notion that this taboo remains in practice even though severe drought and famine conditions have occurred in the region over the past 24 months. However, G. radiata is considered a delicacy by other cultural groups inhabiting the island, and thus it is likely that non-Tandroy travelling along the road collected some individuals. Further, some Tandroy have adopted the practice of selling tortoises along major roads where demand from passing travellers can be high.

Exploitation of this tortoise still occurs in southern Madagascar. Considerable numbers of captive tortoises are kept as pets and often

ORYX VOL 28 NO 2 APRIL 1994 
View of the newly constructed road between Ankororoka and Beloha. Note the steep banks and deep ditches, which trap tortoises in the road bed. The tortoise in the ditch was already dead ( $S$. O'Connor, 30 December 1992).

Dead Madagascar radiated tortoises near Beloha in midOctober 1992. These animals were killed for meat ( $S$.

O'Connor).

ORYX VOL 28 NO 2 APRIL 1994
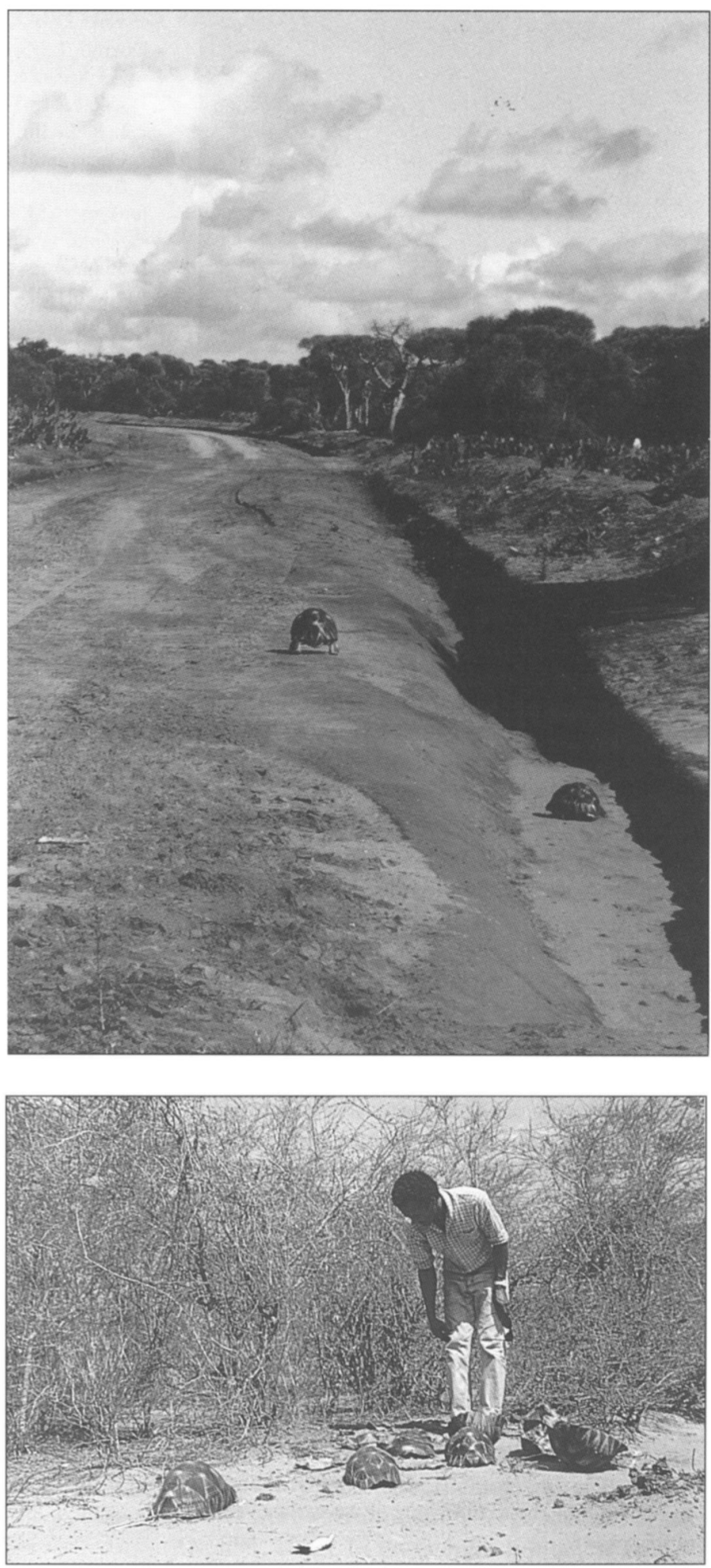

117 


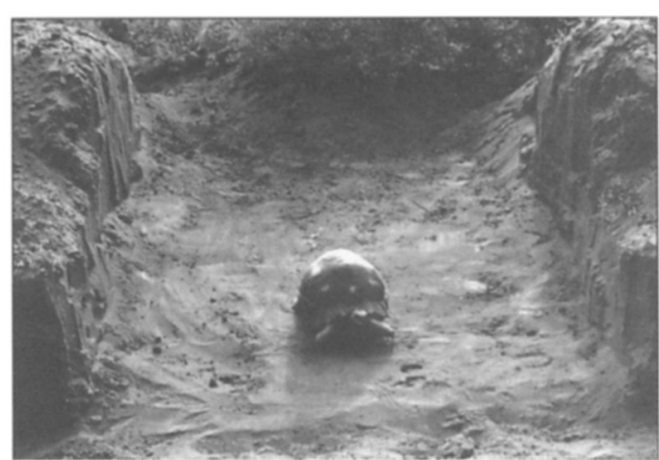

Madagascar radiated tortoise moving down ramp in road bank in late April 1993. After these ramps were put in place the number of tortoises trapped in the road bed declined substantially (S. O'Connor).

in chicken pens - it is a common belief that tortoise urine prevents chicken mite infestations. Non-Tandroy in southern Madagascar continue to collect this animal for food. For example, people associated with the maintenance of the lighthouse facilities at Cap Sainte Marie regularly eat the tortoise; the remains of several hundred tortoises were found behind their compound. Further, although Cap Saint Marie has protected status as a Special Reserve by the Direction des Eaux et Forets (Ministerial Decree No. 62.527, 24 October 1962) and is patrolled by forest guards, we found within the reserve numerous radiated tortoises that had recently been killed by people for meat, and flocks of goats that were rapidly destroying the native vegetation. We also heard numerous reports of commercial exploitation of tortoises in the region by entrepreneurs living in Tolagnaro (Fort Dauphin). Unless steps are taken to reduce the levels of habitat degradation of the remaining natural forests and of exploitation of the radiated tortoise, the prospect for this species and the native biota of the region is bleak. Copies of this report (in French) have been forwarded to the relevant Malagasy governmental institutions and the World Bank.

\section{Acknowledgments}

We are grateful to P. C. H. Pritchard and C. Raxworthy for their comments on an earlier version of this paper.

\section{References}

Durrell, L., Groombridge, B., Tonge, S. and Bloxam, Q. 1989. Geochelone radiata radiated tortoise, sokake. In The Conservation Biology of Tortoises (eds I. R. Swingland and M. W. Klemens), pp. 96-98. Occasional Papers of the IUCN Species Survival Commission, No. 5, Gland. Switzerland.

Jenkins, M.D. (ed.) 1987. Madagascar: An Environmental Profile. IUCN Conservation Monitoring Centre, Cambridge.

Juvik, J.O. 1975. The radiated tortoise of Madagascar. Oryx, 13, 145-148.

\section{Postscript}

After having received our report on the mass mortality of radiated tortoises, the Ministry of Public Works took responsible action. This included building earth ramps through the steep road banks and placing wooden pickets in the opening of drainage canals to block tortoise access. In late April 1993, after the adjustments to the road, S.O'C. revisited the area and found 42 dead and 11 live tortoises along the same stretch of road. In addition 28 tortoises were observed, which appeared to have been collected by people; the remains of these animals were dumped in piles along the road and almost certainly did not die from road entrapment. A radiated tortoise was observed using one of the ramps. Further, the steep banks had also collapsed due to rain, enabling freer movement for the tortoises. It is gratifying to see a ministry acting on advice and providing a grass-roots solution to a real conservation problem.

Steven M. Goodman, Field Museum of Natural History, Roosevelt Road at Lake Shore Drive, Chicago, Illinois 60605, USA and World Wide Fund for Nature, Aires Protégées, BP 738, Antananarivo (101), Madagascar.

Mark Pidgeon, Missouri Botanical Garden, BP 3391, Antananarivo (101), Madagascar.

Sheila O'Connor, World Wide Fund for Nature, Aires Protégées, BP 738, Antananarivo (101), Madagascar. 